\title{
Anthropocentric Nature
}

\section{Lover: Annie Dillard and the}

\section{Transcendentalist Tradition in} American Nature Writing

\section{Fredrik Chr. Brøgger}

University of Troms $\emptyset$

\begin{abstract}
This article situates Annie Dillard's Pilgrim at Tinker Creek within the transcendentalist tradition of American nature writing whose progenitor is Ralph Waldo Emerson. Like Emerson Dillard's fondness for anthropomorphic language is rooted in a spiritual and religious outlook, and becomes so insistent that it spills over into anthropocentrism. Her writing is characterized by two opposing leanings: on the one hand toward the particulars and minutiae of nature in a manner similar to that of a systematic naturalist, and on the other hand, toward an ideal, even Neo-Platonic conception of nature. At the same time, Dillard's transcendental vision of the non-human, living world is revealed to be an anthropocentric one in which biology turns into ideology and nature into culture.
\end{abstract}

Keywords: Nature writing - ecocriticism - American Studies - transcendentalism - anthropocentrism - Annie Dillard - Ralph Waldo Emerson

Annie Dillard is usually regarded as one of the most prominent American nature writers of the second half of the 20th century, in large measure due to her book Pilgrim at Tinker Creek, published in 1974. She is at one and the same time a very modern and a very traditional writer. Within the genre of nature writing we may speak of a transcendentalist tradition that begins with Ralph Waldo Emerson and carries through to John Muir and writers of our own time, including Dillard. In this type of literature the representation of nature tends to be essentialist (nature is seen as a repository of universal and unchanging ideas) as well as religious (nature is seen as God's creation). Due to its essentialist and religious orientation, it is also a literary mode that tends 
to make extensive use of anthropomorphic language, which is to say imagery that endows nature with explicitly human characteristics. In this mode of writing nature is often celebrated in terms of its cognitive importance to man, its relationship to human ideas of ethics, aesthetics and religion. In the writings of Dillard, for instance, the use of anthropomorphic imagery becomes so insistent that the representation of nature is in danger of being usurped by a socio-cultural discourse.

On the one hand nature writers in the transcendentalist tradition often insist on nature's separateness from man; on the other hand, they frequently give expression to pantheistic sentiments. Their view of nature therefore tends to be quite paradoxical: nature is different yet closely related to man, is material and yet mystical, is physical and yet transcendental. To view the world in transcendentalist terms and as God's creation does not, of course, necessarily give man a privileged position in nature; transcendentalism as such could simply be theocentric, regarding God as the center of the universe. In cases such as those of Emerson and Dillard, however, the strong anthropomorphic bent of their language often spills over into an anthropocentric stance. Dillard's figurative discourse in Pilgrim at Tinker Creek may in fact be argued to be as insistently human-centered as Emerson's position in his 1836 pamphlet Nature.

\section{Emerson the Transcendentalist Progenitor}

If we go back to Emerson, the forefather of American transcendentalist nature writing, we see that his essentialism is solidly grounded in his religious outlook, particularly his pantheism, his belief that nature and man are pervaded by the same divine spirit. It is precisely the presence of the Over-Soul in both nature and man that makes "every natural fact" indisputably "a symbol of some spiritual fact" (18). However, here is also the rub in the writings of Emerson and subsequent American transcendentalists: although "[w]ords are signs of natural facts" (17), the essentialist language that gives expression to these facts often has strongly anthropomorphic and ultimately anthropocentric connotations. Emerson is the prototypical example of this, as his anthropocentrism is explicit and pervasive, encompassing everything from the material through the aesthetic to the moral, philosophical, and religious. Physically nature's commodities ("[b]easts, fire, water, stones, and corn") are 
there to "serve" man (11); aesthetically the world "exists to the soul to satisfy the desire of beauty" (17); and ethically "every animal function from the sponge up to Hercules, shall hint or thunder to man the laws of right and wrong, and echo the Ten Commandments" (26). As Emerson puts it, nature is "the great organ through which the universal spirit speaks to the individual, and strives to lead back the individual to it" (37).

The difficulty with this formulation is that the language employed to depict the natural world may end up leading the writer back to his own culture rather than to nature itself. This is a striking tendency in Emerson's Nature.' "A lamb is innocence," declares Emerson; "a snake is subtle spite; flowers express to us the delicate affections" (18). This is a pure projection of our western cultural and religious myths onto nature. The historical and cultural arrogance that lies beneath Emerson's essentialism becomes evident when he declares that nature's "palm-groves and savannahs" were a "fit drapery" for Columbus' triumphant arrival in the New World (15). In such instances nature is read in support of an ideology of western imperialism. Furthermore, philosophical idealism, an important trait in the transcendental tradition of American nature writing, proves to be a very shaky ground for the interpretation of natural phenomena. It tends to cater to an anthropomorphic and even anthropocentric inclination that is hazardous to the health of the language used to describe the natural environment, and perhaps, ultimately, to the health of that environment itself.

Similar essentialist motifs are also prominent in Pilgrim at Tinker Creek. In part, however, Dillard's book seems focused on particulars than on universals. As she puts it in the first chapter, her objective is "to explore the neighborhood, view the landscape, to discover at least where it is that we have been so startlingly set down, if we can't learn why" (24). She wants to see "where we so incontrovertibly are." "It's common sense," she tells us, "when you move in, you try to learn the neighborhood" (118). This focus on the where makcs Pilgrim promise an accurate, factual and naturalistic representation of her surroundings, which it in many ways is (and Emerson's Nature is not). Her statement proves, however, to be an incomplete rendering of her own aims. When describing her neighborhood she also turns out, like Emerson, to

1. Critics disagree sharply, however, about Emerson's view of the natural world in Nature. Stephen E. Whicher argues that Emerson attempts "to assimilate nature into himself, to reduce the NOT ME to the ME" (52), and Joel Porte argues that Emerson makes nature "completely ancillary to moral science" (61). For a different view, see for instance Robert D. Richardson who argues that Emerson believes "that nature bats last, that nature is the law, the final word, the Supreme Court" (97). 
be constantly concerned with speculating on the larger questions to which this environment, in her view, gives rise. As she puts it in the fifth paragraph of her opening chapter, Tinker and Carvin's creeks represent "the mystery of the continuous creation and all that providence implies: the uncertainty of vision, the horror of the fixed, the dissolution of the present, the intricacy of beauty, the pressure of fecundity, the elusiveness of the free, and the flawed nature of perfection" (16). These are issues that far surpass questions of where; they concern hows and whys and wherefores.

As befits a transcendentalist, Dillard's concern is ultimately a spiritual and religious one. ${ }^{2}$ As she notes at the end of Chapter One when describing a breeze that crumples the creek's water, "the breeze is the merest puff, but you yourself sail headlong and breathless under the gale force of the spirit" (25). It often takes very little of physical impressions to propel Annie Dillard into dizzying transcendental sensations on a par with Emerson's own. In Linda L. Smith's view, Pilgrim at Tinker Creek "appears to be a book about the natural world" but "in reality it is about God and his relationship to man" (16). In my view, this is overstating the case. What typifies Dillard's writing about her Blue Ridge ${ }^{3}$ surroundings is instead the constant vacillation between her concrete, detailed, sharp, and fresh renderings of natural life and her speculative, abstract, and mystical bent. This doubleness in her writing, as characterized by constant shifts between a material and a spiritual vision, is what makes Pilgrim at Tinker Creek a typical example of the American tradition of transcendentalist nature writing. ${ }^{4}$

2. In the chapter on Dillard in Nature's Kindred Spirits, James I. McClintock even argues that a religious orientation informs American nature writing as a whole: "In fact, nature writing in America has always been religious, if unorthodox. Without doubt, that is true of essays by Thoreau, John Muir, John Burroughs, Edwin Teale, and, as we have seen, Also [sic] Leopold and Joseph Wood Krutch, whose works comprise more than a century of American nature writing" (89).

3. The "Blue Ridge," so called in Virginia and North Carolina, consists of the first line of the mountains that mark the eastern boundary of the Appalachian highlands.

4. Dillard herself acknowledges her indebtedness to both Thoreau and Emerson in Pilgrim at Tinker Creek. Her book is by a great many critics linked to American transcendentalism, but they define its relationship to that tradition differently. In her book on Dillard, Linda L. Smith declares for instance that Dillard's theology is "less idealistic, more intrinsically mystical, and much less optimistic than transcendentalism" (16); " . . Pilgrim at Tinker Creek is post-transcendental - that is, arising from but extending beyond that tradition" (45). Like Smith, many critics also note Dillard's relationship to (Christian) mysticism; Scott Slovic refers for instance to her "rejuvenation of the mystical tradition in literature" (62). 


\section{Dillard the Naturalist}

Let us start with Annie Dillard, the detailed, systematic naturalist. Her book is filled with minute descriptions and lists of natural phenomena, their physical and/or behavioral characteristics. In her fascination with accuracy of observation she resembles Thoreau more than Emerson. Take for instance her description of the life of a duck pond in spring:

The pond is popping with life. ... Diatoms, which are algae that look under a microscope like crystals, multiply so fast you can practically watch a submersed green leaf transform into a brown fuzz. . . . Stillwater caddises, alderfly larvae, and damselfly and dragonfly nymphs stalk on the bottom debris: mayfly nymphs hide in the weeds, mosquito larvae wriggle near the surface, and red-tailed maggots stick their breathing tubes up from between decayed leaves along the shore. Also at the pond's muddy edges it is easy to see the tiny red tubiflex worms and bloodworms; the convulsive jerking of hundreds and hundreds together catches my eye. (111)

Such a passage testifies to the meticulous sense of detail and the evocative freshness of Dillard's discursive prose: she observes how algae "transforms into a brown fuzz," how caddises and larvae and nymphs "stalk on the bottom debris," how mosquito larvae "wriggle near the surface," and how tubiflex worms and bloodworms "jerk" at the pond's "muddy edges." Her concern with descriptive accuracy is found in passage after passage focusing on the behavior of different animals along the creek, large or small. Dillard's style is itself a direct illustration of her explicit desire, as she evokes it time and again, to note the "extravagance of minutiae" of creation (119), to reveal the intricacy of its "spotted and speckled detail" (119), to keep herself open to the meaning "of the shreds of creation that flourish in this valley," to impress herself "at all times with the fullest possible force of their very reality" (126), to note the "scandal of particularity" of the world (79), and to be "in the clustering thick of things, rapt and enwrapped in the rising and falling real world" (195).

Sometimes Dillard's use of figurative imagery intensifies her evocation of nature's physicality. This is for instance the case in her description of a mountain illuminated by a sunset: "Shadows lope along the mountain's rumpled flanks, they elongate like root tips, like lobes of spilling water, faster and faster. A warm purple pigment pools in each ruck and tuck of the rock; it deepens and spreads, boring crevasses, canyons. . . . The ridge's bosses and hummocks sprout bulging from its side . . " (78). By evoking one natural phenomenon metaphorically in terms of another, in this case the increasing shadows of the sunset in terms of the movement of animals and plants and 
water, she makes the play of shadow and light come alive: mountains have flanks, shadows "lope" and "elongate like root tips," and light is like water that "pools" and "spreads, boring crevasses, canyons." Her imagery multiplies our sense impressions of the world's substance, turning even the immateriality of shadow into something tangible. This is the style of Dillard the naturalist at the height of her literary powers, combining a pervasive sense of concrete detail with intensely imagistic and metaphorical uses of language.

At the same time, however, her writing often gives expression to her experience of being distanced from nature. Sometimes her vision of the natural environment becomes that of an amoral, postmodernist universe where suffering, death, and grace seem "wholly gratuitous" (118). Her style is suffused with her constant, self-reflexive attempts to come to terms with this side of nature. This is particularly true when she describes the world of lower life forms, for instance the lives of insects, whose grotesque means of mass reproduction, death, and survival keep terrifying her (parasites eating away at their hosts, parents devouring their offspring or vice versa), forcing her to ask whether "this world, my mother, is a monster, or I myself am a freak" (158). Particularly in the middle parts of her book, Dillard is repulsed by a natural environment that is "an assault on human values" (146); a place in which "anything goes" (124) and "[e]very glistening egg is a memento mori" (145); a nature of "[h]olocaust, parody, glut" (151), of "a universal chomp" (151). Such violent, partly anthropomorphic language reveals that her book is first and foremost a search for metaphysical answers to questions that literally keep her awake at night. In the last three chapters of Pilgrim at Tinker Creek, however, her tone is increasingly affirmative in its acceptance of both nature's grimness and its beauty.

Her observations about the vibrant life of Tinker Creek seem nonetheless quite often to be those of an outsider and a visitor. Her richly evocative language does not only function to make the familiar seem strange (which is to say, serving as a technique of defamiliarization in Viktor Shklovsky's sense of the term); it also bears the marks of an estrangement from nature itself. Scott Slovic notes, "Dillard requires the 'otherness' of nature to stimulate the prized emotions of surprise and uncertainty, the feeling of looking mystery in the eye" (84). Dillard characterizes herself as "a fugitive and a vagabond, a sojourner seeking signs" (234). The title of her book is in a sense quite apt: she is indeed a pilgrim in nature, a devotional sojourner in search of a shrine or a holy place. The word pilgrim comes from Latin peregrinus, a compound of the words per ("through") and ager ("land"), specifically designating a 
traveler in foreign parts. That sense is also important in Dillard's book. In some ways nature is a foreign territory to her, as it also was for the group we often refer to as the Pilgrims, the English Puritans who in founding the Plymouth Colony in 1620 came face to face with an enormous, non-human wilderness. Like them, Dillard - particularly when confronted with the enormities of entomological life - is constantly trying to forge a transcendental context into which the world of brute nature may be seen to fit.

\section{Dillard the Transcendentalist}

Dillard's transcendentalist perspective is particularly evident in Chapter Two, a reflection on the problematics of "Seeing." Although she speaks of the importance of training ourselves to see minutely and systematically and points to the difficulty in seeing what we do not expect to see in advance, she also celebrates "another kind of seeing that involves a letting go" (40). This is a state of mind that allows the mind's "muddy river" to "flow unheeded" and to make you gaze "into the realm of the real where subjects and objects act and rest purely, without utterance" (41) - which is to say wordlessly and untainted by the cultural distortion inherent in language. For Dillard these are instances of seeing "truly" (41); she describes such a moment as an experience of transcendence: "something broke and something opened. I filled up like a new wineskin. I breathed air like light; I saw a light like water. I was the lip of a fountain the creek filled forever; I was ether, the leaf in the zephyr; I was fleshflake, feather, bone" (40-41).

Dillard's conception of nature, then, echoes the inclination towards NeoPlatonic idealism in American Romantic writers. Nature is indisputably God's creation and its beauty essentially a transcendental and pantheistic phenomenon. This is most clearly seen in her vision of what she calls "the tree with the lights in it," a cedar which appears to be "buzzing with flame" as she stands on the grass "that was wholly fire, utterly focused and utterly dreamed. It was less like seeing than like being for the first time seen, knocked breathless by a powerful glance" (42). After the experience has abated, she is "still ringing": "I had been my whole life a bell, and never knew it until at that moment I was lifted and struck. I have since only very rarely seen the tree with the lights in it. The vision comes and goes, mostly goes, but I live for it, for the moment when the mountains open and a new light soars in spate through the 
crack, and the mountains slam" (42). This is an experience that seems very closely related to Emerson's sensation of becoming a "transparent eyeball": "Standing on the bare ground, - my head bathed by the blithe air, and uplifted into infinite space, - all mean egotism vanishes. I become a transparent eyeball. I am nothing. I see all. The currents of the Universal Being circulate through me; I am part or particle of God" (996). Ultimately, Dillard's nature, like that of Emerson, is pervaded by spirit. "Something pummels us," says Dillard at the end of her first chapter, playing on the scene with her cat's paws, "something barely sheathed. Power broods and lights. We're played on like a pipe; our breath is not our own" (24).

\section{Dillard the Anthropocentrist}

In Dillard's writing, however, such a pantheistic vision of nature continuously turns into an anthropocentric one. It becomes quite clear already on the very first page of Pilgrim at Tinker Creek that her book is first and foremost motivated by her own strong need to find spiritual answers to the meaning of disturbing natural phenomena. She famously opens her book with the story of a cat she used to have. The cat would jump into her bed after a night's hunting and would cover her body with bloody, rose-like paw prints. For Dillard these paw prints immediately assume religious and anthropomorphic dimensions:

It could have been the rose of union, the blood of murder, or the rose of beauty bare and the blood of some unspeakable sacrifice or birth. The sign on my body could have been an emblem or a stain, the keys to the kingdom or the mark of Cain. I never knew. I never knew as I washed ... whether I'd purified myself or ruined the blood sign of the passover. We wake, if we ever wake at all, to mystery, rumors of death, beauty, violence. (15)

The cat's footprints are not considered as signs of animal predation, not even as a point of departure. Instead Dillard transposes the paw prints into human and cultural emblems, as indicated by words such as "murder," "unspeakable sacrifice," and of course phrases such as "passover" or "the keys to the kingdom" or "the mark of Cain." We enter a world of religious and social discourses about the mysteries of death, redemption, and damnation, rather than the mysterious world of animal behavior. Like the Pilgrims, and like Emerson and Thoreau before her, Dillard is an incurable symbolist and anthropomor- 
phist. Her objective in Pilgrim at Tinker Creek is first and foremost, as she herself puts it, "to keep here what Thoreau called 'a meteorological journal of the mind,' telling some tales and describing some of the sights of this rather tamed valley, and exploring, in fear and trembling, some of the unmapped dim reaches and unholy fastnesses to which those tales and sights so dizzyingly lead" (24).

Dillard's phenomenal world of the nature of Tinker Creek is one that constantly turns into a mirror of her own mind, not least her own socio-cultural ideas and attitudes. The animal sounds that she hears in the summer night are a case in point:

Cicadas - which Donald E. Carr calls 'the guns of August' - were out in full force. Their stridulations mounted over the meadow and echoed from the rim of cliffs, filling the air with a plaintive, mysterious urgency. I had heard them begin at twilight, and was struck with the way they actually do 'start up,' like an out-of-practice orchestra, creaking and grinding and all out of synch. It had sounded like someone playing a cello with a wide-toothed comb. The frogs added their unlocatable notes, which always seem to me so arbitrary and anarchistic ... (191)

In such passages nature becomes strikingly human, not so much because the sounds of cicadas are compared to those of an out-of-practice, creaking orchestra, a jocular and curiously appropriate personification, but because both the cicadas and the frogs are linked to deeper psychological or cultural phenomena, as when the former are seen to sing "with a plaintive, mysterious urgency" and the latter croak their "arbitrary and anarchistic" notes. This is no longer first and foremost a phenomenal landscape of natural creatures but instead one of emotional and cultural projection. Similarly, a maple key falling through the air towards the end of Pilgrim becomes emblematic of a certain measure of choice and free will ("If I am a maple key falling, at least I can twirl" [235]).

Effectively, the conclusions that Dillard draws in her observations of nature are more closely connected with the ideology of western culture and religion than with nature as such. Her summary observations in the chapters on "Intricacy" and "Fecundity" are the culminations of this anthropocentric tendency. Her detailed and extensive descriptions of the intricacies and extravagancies of the natural world lead her to express a sense of amazement: "it all flows so freely wild, like the creek, that it all surges in such a free, fringed tangle. Freedom is the world's water and weather, the world's nourishment freely given, its soil and sap: and the creator loves pizzazz" (125-26). The root word 
"free" is repeated no less than four times in these two sentences; such a high frequency of the word is more commonly found in, say, Norwegian Independence Day speeches or American State of the Union addresses. Dillard's linking of freedom to "soil" and "sap" is at the same time quite problematic because such organicist imagery serves to "naturalize" a cultural concept and obscure its socio-historical origins.

Her reader is furthermore at a loss to see exactly when and how this transition from the idea of intricacy to the concept of freedom was made in the first place, but suspects that such a transcendentalist leap from matter to spirit may be linked to the Genesis and the Christian concept of the 'happy fall' ${ }^{5}$ Observing the microscopic life of rotifers, daphnia, and copepods, Dillard writes for instance that "I was created from a clot and set in proud, free motion: so were they. So was this rotifer created . . " (113). To portray the motion of microscopic creatures in terms of pride and freedom is to blatantly anthropomorphize natural phenomena.

To link the idea of freedom to the natural environment is not, however, an uncommon phenomenon in American literature. Other American nature writers such as Thoreau (in his essay "Walking") and Gary Snyder (in his book The Practice of the Wild) also reveal a similar propensity for making the wildness of nature synonymous with the idea of freedom, a concept of Euro-Western ideology and political philosophy. And in Dillard's conclusion to the Intricacy chapter, concepts and figures of speech of American culture can be seen to abound to the extent that the reader is no longer sure whether it is the natural environment or the American ideology of the Open Society that is being presented:

The wonder is - given the errant nature of freedom and the burgeoning of texture in time - the wonder is that all the forms are not monsters, that there is beauty at all, grace gratuitous, pennies found, like the mockingbird's free fall. Beauty itself is the fruit of the creator's exuberance that grew such a tangle, and the grotesques and horrors bloom from that same free growth, that intricate scramble and twine up and down the conditions of time. (133)

Despite the brilliant figures of speech that link creation and time to something that burgeons and grows, nature is once again put to the service of culture. Dillard's is a linguistic strategy through which ideas of freedom are natu-

5. Reference is to Gary Mcllroy's observation that "Joining Christian theology and transcendentalist vision, Dillard gives new meaning to the idea of the 'happy fall.' Not just Christ but creation itself is a measure of divine grace, through which the imaginative mind might make a paradise of thistles" (159). 
ralized by the vegetative imagery of fruition, growth, and bloom. Her language evokes not so much a landscape as an anthropocentric mindscape of grotesques and horrors (of anti-humanism), of gratuitous grace (of Christian belief), of pennies found (of monetary society), and of freedom (of American culture), however errant. In the course of the rhetoric of Dillard's conclusion, the nature of Tinker Creek is endowed with characteristics that come discomfortingly close to that other American environment, the economic, political, and ideological world of free and unchecked growth, a socioeconomic system which is commonly said to quite "natural" and which, for all its obvious blemishes, is often declared to be the best of all worlds.

\section{Conclusion}

In American nature writing there is a prominent tradition in which the physical, detailed description of the landscape is combined with a transcendental stance. In the writings of both Emerson and Dillard this stance seems almost inescapably to lead to a homocentric vision of life, a trend that we find in many other American nature writers as well, although not always as explicitly as in Nature and Pilgrim at Tinker Creek. In both Emerson and Dillard's writing representation all too often turns into overt construction at the drop of an image, geography turns into a meteorology of the mind, phenomena turn into transcendental truths, biology turns into ideology, and nature turns into culture.

\section{Works Cited}

Dillard, Annie. 1974. Pilgrim at Tinker Creek. London: Picador, 1976.

Emerson, Ralph Waldo. 1971. "Nature." The Collected Works of Ralph Waldo Emerson. Vol. 1. Ed. Alfred R. Ferguson. Cambridge, MA: Harvard UP.

McClintock, James I. 1994. Nature's Kindred Spirits: Aldo Leopold, Joseph Wood Krutch, Edward Abbey, Annie Dillard, and Gary Snyder. Madison: U of Wisconsin P.

McIlroy, Gary. 1984. "'The Sparer Climate for Which I Longed': Pilgrim at Tinker Creek and the Spiritual Imperatives of Fall." Thoreau Quarterly, 16: 156-61.

Richardson, Robert D., Jr. "Emerson and Nature." 1999. The Cambridge Companion to Ralph Waldo Emerson. Ed. Joel Porte and Saundra Morris. Cambridge: Cambridge UP, 97-105. 
Porte, Joel. 1966. Emerson and Thoreau: Transcendentalists in Conflict. Middletown, CT: Wesleyan UP.

Shklovsky, Viktor. "Art as Technique." Literary Theory: An Anthology. Eds. Julie Rivkin and Michael Ryan. Malden, MA: Blackwell, 1998. 16-23.

Slovic, Scott. 1992. Seeking Awareness in American Nature Writing: Henry Thoreau, Annie Dillard, Edward Abbey, Wendell Berry, Barry Lopez. Salt Lake City: U of Utah P.

Smith, Linda L. 1991. Annie Dillard. New York: Twayne.

Whicher, Stephen. 1953. Freedom and Fate: An Inner Life of Ralph Waldo Emerson. New York: A.S. Barnes, 1961. 